Marquette University

e-Publications@Marquette

Library Faculty Research and Publications

Library (Raynor Memorial Libraries)

$1-1-2006$

Digitization, Donor Relations, and Undergraduate Instruction

Matt Blessing

Marquette University, matt.blessing@Marquette.edu

Published version. Microfilm \& Imaging Review, Vol. 35, No. 3 (2006): 93-97. DOI. (C) 2006 Walter de Gruyter. Used with permission. 


\title{
Digitization, Donor Relations, and Undergraduate Instruction
}

\author{
by Matt Blessing
}

\section{Developing Donor Relations}

Collection development archivists know that building a partnership with a potential donor may take years, occasionally decades. From the perspective of a donor, contributing unique materials to an archival repository a local historical society, academic archives, or a research library can be an emotionally complicated process. A donor must have acquired a degree of separation from the material, but also have a deep sense of trust in the repository soliciting the records. Often, the initial contribution to a repository consists of records void of sentimental or financial value. As the relationship between a donor and a repository strengthens, donors (hopefully) begin contributing more noteworthy and revealing materials, including personal correspondence, diaries, and photographs. This scenario is rou- tine not only with the acquisition of personal papers, but the records of businesses, membership organizations, and all other kinds of archival records.

\section{St. Francis Mission Records at Marquette University}

In 1977 the Department of Special Collections and University Archives (SPARC) at Marquette University established a partnership with St. Francis Mission on the Rosebud Indian Reservation. Established in 1886, the Indian mission $^{1}$ at St. Francis has been continually staffed by Catholic priests from the Society of Jesus (Jesuits) for 120 years. Pre-dating South Dakota's admission into the Union, these historical records contain substantial information about the Indian school, parish activities, and the mission's varied services to the Native American population. The records also provide a rich documentary record about the Rosebud Sioux's (or Si-
Matt Blessing (matt.blessing@ marquette.edu) is Head, Department of Special Collections and University Archives, Raynor-Memorial Libraries, Marquette University. cangu Oyate) language, culture, and recent history. One of the cornerstone collections within SPARC's Native American Catholic manuscript program, the records of St. Francis Mission have attracted a broad audience of users, including faculty, independent writers, graduate students, and family historians. In addition to the learning and scholarship opportunities, preservation of these research collections is an extension of Marquette University's heritage as a Catholic and Jesuit institution. Amounting to over thirty cubic feet of material, the collection consists of a variety of record formats, including text, analog sound recordings, motion picture film, and videotape. Following the acquisition pattern described above, however, a vast collection of historic photographs did not become available until late 2005, almost three decades after the partnership between SPARC and St. Francis Mission had been formed. 


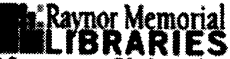
Marquette University

\section{St. Francis Mission Images}

home : browse : advanced search : preferences : my favorites : help

back to results : $:$ add to favorites : reference uri

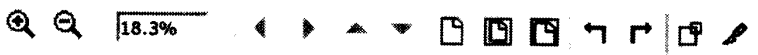

Nine giris and nun knitting during $\mathrm{Ww}, 1917$ - 1918
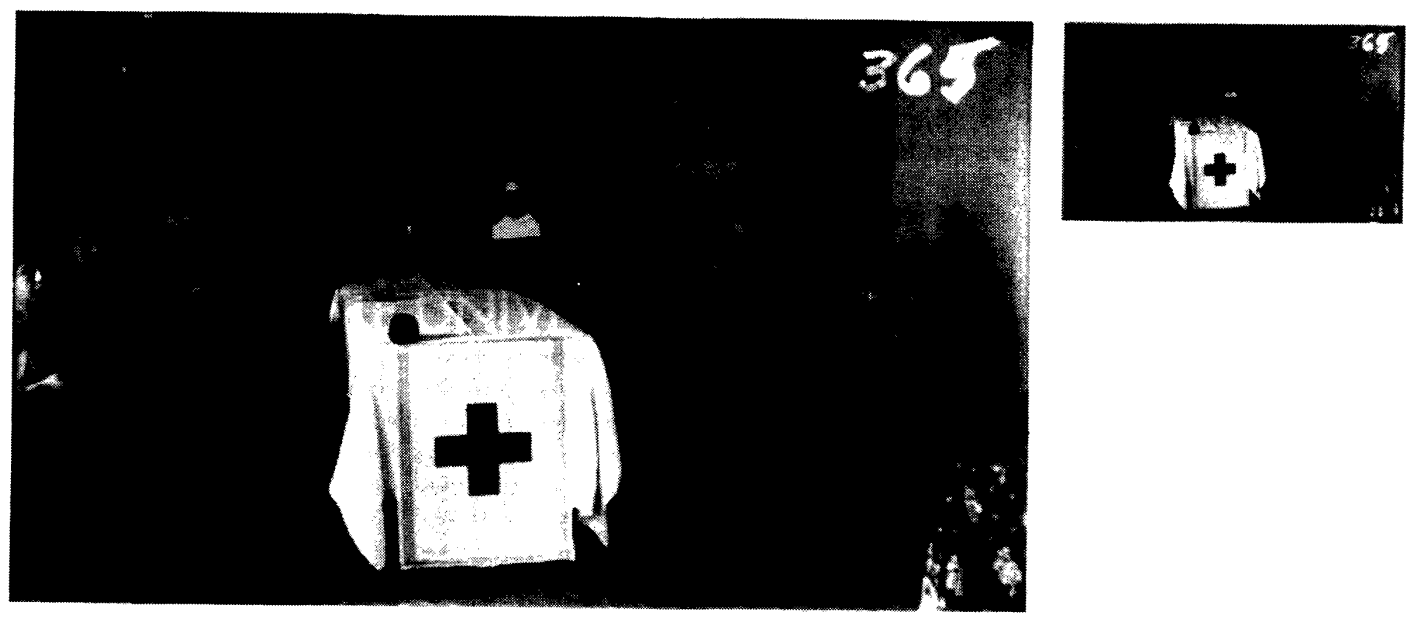

Titie

Nime gris and nun kniting during ww!, $1917-1918$

Date of Photograph $1917-1918$

Notes

Folowing information prowice by The Euechel Lakota Memorial Museum: Giris knitting during World War 1: [Seated, L to R]

Olle Hood (Kelle), Fanne Hunts Horse, Frfie Knkade, Suste Bordeaux, Grace Whirwind Soldier, Sister Camelta, Agnes Sore Eyes, Cora Owns The Fire (bad Wound), Paume Hudson, and Minrier Habl Shit.

Subjects Indian youth - South Dakota Negatve no, Same as Identifier

indians of Norn America-. South Dakota

knithing 1910 -1920

Nurs - South Dakota

Sisters of St. Francs of parance and Christian Charicy - South Dakgta

Worl War, 1914 1919 marticipation, Indian

Location Depicted

South Dakota--Rosebud Indan Reservatson--St. Francis--St. Francis Mission

Ethnic Group

Brule Indians tsicangu, Lakota Teton Sloux

5 FM_6-6_0365

Identifier

Collection

Publisher

St. Francis Mission Records: $06-6$

Type

Marquette University, Department of Special Collections \& University Archives

Image

Physical Description

Digital Reproduction

Information

Copyright

Gelatin Dry Plate, $8.2 \times 13.8 \mathrm{~cm}(31 / 4 \times 55 / 16 \mathrm{in}$.)

Scanned with Microtek ScanMaker $9800 \times L$ at 600 dpi. Display image is jpeg generated from the archival tiff and psd.

This image is issued by Marquette University Libraries. Use of the image requires written permission from the staff of the Department of Special Collections and University Archives. It may not be sold or redistributed, copied or distributed as a photograph, electronic file, or any other medle. The image should not be significantly altered through conventional or

electronic means. Images altered beyond standard cropping and resizing require further negotiation with a

The user is responsible for all issues of copyright. Please Credit: Department of Special Collections and University Archives, Marquette University Libraries.

Ordering Information

Learn more about this http://www marquette. du/horary/colections/archives/Msa/SFM/SFM-Schtml

collection

back to results : : add to favorites : reference url

previous : next

powered by CONTENTdrn \& contact us

$\wedge$ to top $\wedge$

Figure 1. Nine girls and nun knitting during WWI, 1917-1918. Due to the efforts of a local museum and community volunteers, many of the images within the digital St. Francis Mission Images collection contain detailed descriptions. Archivists included this information within the Notes Field, in this instance featuring the maiden and married names of the individuals depicted in the image. SFM 6-6, No. 0365. 
More than 40,000 negatives and photographic prints had been preserved and made accessible at the Buechel Memorial Lakota Museum, located on the grounds of the St. Francis Mission. The museum staff regularly used this photo collection for exhibitions and publicity, while community members visited the museum to find images of relatives who had attended the mission school or were members of the Catholic parish. The photo collection also included images of Sicangu Oyate's culturally sensitive ceremonial practices, such as the Sun Dance. Several thousand images made by Rev. Eugene Buechel, S.J. (1874-1954) are especially important for their ethnographic value. A deeply trusted and respected member of the reservation community, Father Buechel captured everyday activities that are valuable to cultural anthropologists and social historians.

Although this historic collection of photographs was the property of the Wisconsin Province of Jesuits ${ }^{2}$, the current Jesuit administrators and Marquette's archivists recognized the need to balance archival preservation and scholarly access, yet also maintain convenient access to the collection for the 13,000 residents of the Rosebud Indian Reservation.

The collection of photographic negatives acquired from the Buechel Museum offered a nearly complete example of amateur photographic processes over the past 125 years. Negative formats included gelatin dry based emulsion (1880-1925), cellulose nitrate, (1889-1938), cellulose acetate (1925-present), polyester "safety" film (1955- present), among others. Itemlevel description of the images coordinated years earlier by the staff at the Buechel Museum had involved volunteers from the reservation community. Tribal members had identified hundreds of students and other Sicangu Oyate associated with the Catholic mission during the early decades of the twentieth century. Indeed, many of the photographs depicted the parents and grandparents of these volunteers. Although this information required a considerable amount of verification and editing in order to use as metadata, it proved invaluable to archivists who directed the digitization efforts from one thousand miles away. Indeed, the level of detail provided by the Buechel Museum offered Marquette's archivists a unique opportunity to build a digital collection that served both scholars and genealogists. $^{3}$

Several of the major Native American collections at Marquette have been microfilmed in order to address both preservation concerns and issues of access. Formal collection agreements with several donors require the archives to furnish a complete copy - usually on $35 \mathrm{~mm}$ microfilm - of all textual materials maintained by Marquette University to a library, museum, or community center on the reservation so that community members have convenient access to this important part of their documentary heritage. Marquette has also donated microfilm readers to several mission museums. Recent developments in digital scanning have permitted the archives the opportunity to augment existing collections. Both parties agreed that digitization of photographic materials - unlike the microfilmed printed materials would be highly selective. Several factors informed this decision, such as the labor costs involved in scanning and metadata creation, the long-term maintenance costs associated with digital collections, and the higher degree of subject duplication within the photographic collection.

\section{Digitization and Undergraduate Instruction}

The historic images from the Rosebud Indian Reservation also offered a hands-on learning opportunity for undergraduates within Marquette's interdisciplinary public history program. ${ }^{4}$ "Technology for Historians" is a three-credit upper-level course for history majors, introducing them to new media technologies for presenting and preserving historical materials. The course is co-taught by faculty from Marquette's history department, instructional media center, and archives. Students are introduced to advanced $\mathrm{html}$ editors, audio and video streaming technology, CD/DVD production, in addition to digital imaging and cataloging.

A major component of this semester-length course involved instruction on the handling, cleaning, arrangement, and scanning of historic negatives from St. Francis Mission. This portion of the course was taught by the university archivist and the university photographer. Students received a primer on $20^{\text {th }}$ century photographic processes. They also learned the 


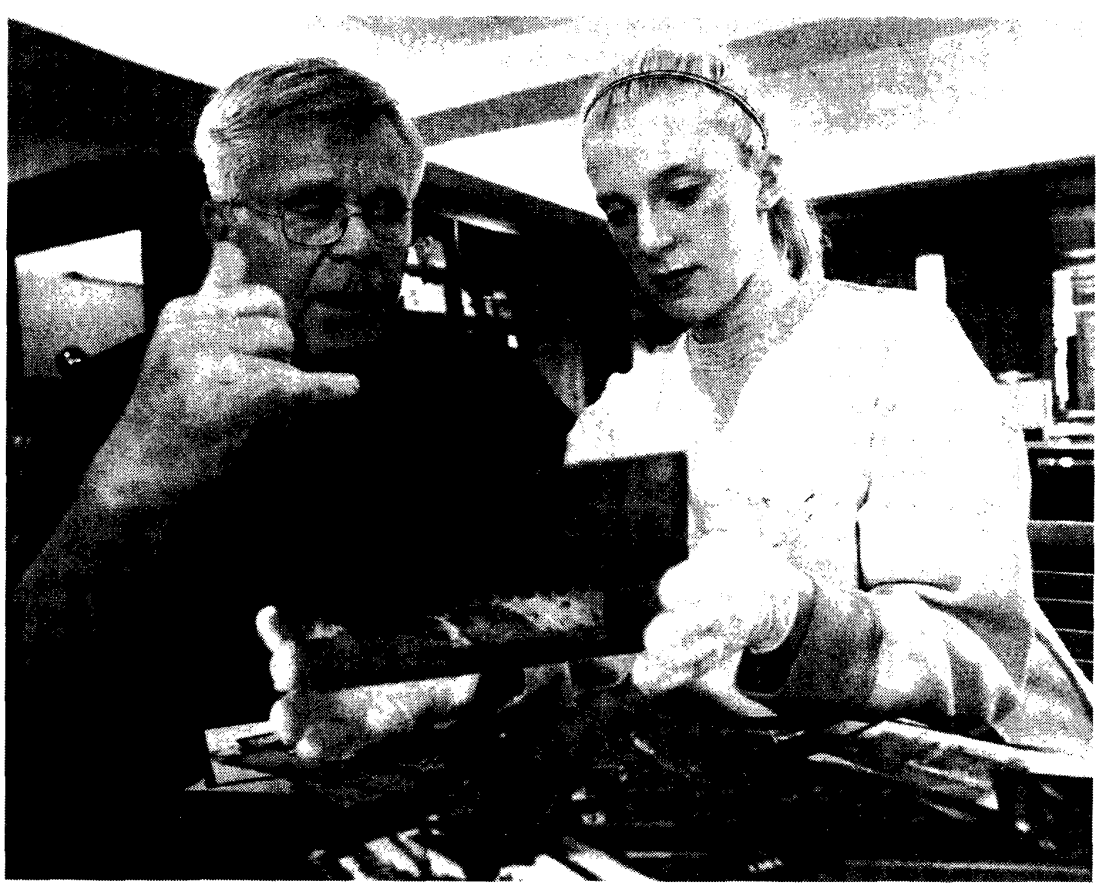

Figure 2. Alisyn Stuebner, a Marquette University history senior, works with photographer Don Doll, S.J., a guest instructor from Creighton University, on identifying subjects in a negative from St. Francis Mission. Photograph by Dan Johnson.

proper techniques for handling and caring for glass plate negatives: lint-free cotton gloves, dusting of negatives with a camels-hair brush, proper environmental and storage conditions, and so forth. Each of the twelve undergraduates enrolled in the public history course had some (albeit nominal) experience with scanning software. With the goal of developing a digital archival collection, instructors sought to balance their instruction, emphasizing the critical need to maintain the historic integrity of the original image, while also introducing students to advanced scanning techniques that improved the overall quality of the digital image. In coordinating the "digi- tization lab," professional archivists were "on call" to assist undergraduates who encountered difficulties or had questions during the assignment, a project that required four weeks to complete.

Since development of the St. Francis Mission Collection was a teaching project, students scanned and saved all images as Photoshop documents (psd), then subsequently made their adjustments as TIFFs. By insisting on two versions of each image - both the unaltered psd and the edited TIFF - archives staff could correct the work of overzealous in cropping and adjusting contrast levels. Resolution specifications determined a few students who had been for previous digitization projects were utilized. DPI ranged from 300 dpi for 8" x 10" glass plates to 600 dpi for 3 " $\times 5$ " negatives.

Both sets of digital scans were temporarily saved to a $400 \mathrm{~GB}$ external hard-drive, purchased for the class project. Students were required to sign-up in advance in order to use the computer scanning equipment; the historic negatives always resided within the secure and monitored archives reading room. Each student was advised to save the images that they had been assigned to a USB memory stick - de rigueur equipment among undergraduates in 2006.

Archivists had previously selected 160 negatives from the collection as the initial set for digitization, images that documented a variety of activities in and around the Catholic mission. Images with exceptional descriptions were also identified for digitization. To protect personal privacy, archivists avoided all images of children or celebrations of Catholic sacraments dated after 1935 . In addition, archivists omitted images of $\mathrm{Na}$ tive religious ceremonies and related objects deemed inappropriate by the Sicangu Oyate for public viewing.

The "archival lab work" by undergraduates totaled approximately 60 hours, an average of 2.7 images per hour. While this average seems painstakingly slow, it should be remembered that students dusted each negative and evaluated its physical condition. Students also identified each image, inserting the negative into an acid-free envelope and labeling it according to instructions provided by the archivist. Most importantly, 
none of the glass plates were damaged during the processing and scanning process.

Utilizing CONTENTdm, two members of the professional staff prepared all metadata for the project, while a third subject specialist was responsible for final editing and approval of metadata. Project developers offered two methods of searching: (1) keyword, or (2) a pulldown menu with 15 broad subject-terms: Arts \& Crafts, Dance, Education, Recreation, Religion, and so forth. These subject terms were built into the program as a hidden field. Both the collection homepage and individual image records offered hyper-text links to the descriptive inventory for other parts of the St. Francis Mission Collection. Labor involving the professional staff totaled 110 hours, including: team conceptualization of the project, development of controlled vocabularies, preparation of metadata, graphic design (completed by a Systems Librarian), and project publicity.

\section{Conclusion}

The instructors of the public history course were especially pleased that the digitization project offered a balance between classroom theory and practical hands-on experience. Skills acquired as a result of the assignment prepared several students for internships at mu- seums and archival repositories. In evaluating the class, students commented consistently that they considered the digitization project - which was available for viewing by the end of the semester - as the most valuable aspect of the course.

Archivists benefited by launching a digital collection less than six months after acquisition of the negatives. The digitization project hopefully strengthens the ongoing relationship with the donor. Online visitation has also been impressive, especially considering the collection's relative small size. During the first three months of online accessibility, the St. Francis Mission Collection logged 5,050 page views - with individual images viewed an average of 31 times. Significant additions to the digital collection are planned. Due to their physical instability, cellulose nitrate film will be prioritized so that original negatives can be stored in off-site in a controlled environment. These will include many images by Rev. Eugene Buechel, S.J., images documenting the history of St. Francis Mission, and also Holy Rosary Mission, located on the Pine Ridge Indian Reservation.

\section{Notes}

${ }^{1}$ Among religious orders, a mission may be defined as a church and residence serving as a headquarters for evangelization.
Typically the operations include self-sufficient enterprises (e.g. farm, ranch, school, carpentry shops, radio station, museum) on nearby lands.

2 St. Francis Mission was established by Jesuits from the German Province's Buffalo Mission. Administration of St. Francis Mission was transferred to the Turin Province's Rocky Mountain Mission in 1907, to the California Province in 1909; to the Missouri Province in 1912; and most recently to the Wisconsin Province in 1955.

3 St. Francis Mission Images, http://digitalmarquette.

cdmhost.com/SFM

${ }^{4}$ Michael Gordon, a leading public historian, suggests that "public history most often refers to the employment of historians in history-related work outside of academia, and especially to the many ways in which historians recreate and present history to the public - and sometimes with the public. Thus, we find historians working in archives, museums, historic sites, state and local historical agencies, newspapers, businesses, trade and labor organizations, and in all levels of government. They work as editors, archivists, oral historians, administrators, curators, historic preservation specialists, writers, public policy analysts - and, lest we forget, as historians!" Text from Dr. Gordon's the syllabus for "Introduction to Public History," taught at the University of Wisconsin-Milwaukee. 